\title{
KEANEKARAGAMAN JENIS SERANGGA PADA TANAMAN TERUNG BELANDA (Solanum betaceaum) DI DIENG KULON JAWA TENGAH
}

\author{
Nurmaisah Nurmaisah ${ }^{1 *}$, Deny Murdianto ${ }^{2}$ \\ ${ }^{1}$ Jurusan Agroteknologi, Fakultas Pertanian, Universitas Borneo Tarakan \\ ${ }^{2}$ Jurusan Agribisnis, Fakultas Pertanian, Universitas Borneo Tarakan \\ *Email: nurmaisah28@yahoo.com
}

Receive: 27 September 2019

Accepted: 18 Oktober 2019

\begin{abstract}
Tamarillo (Solanum betaceaum) is shrub, of Solanaceae family member. This species cultivated at warm temperate region $20^{\circ} \mathrm{C}$. Tamarillo only grew in highland, above $1000 \mathrm{~m}$ from sea surface level. The aims of this research were to know the diversity and insect species abundance land and to know the potential role of insects that was beneficial and harmful on tamarillo plants at Dieng. The diversity of insect species was obtained from catching insect directly using insect net and indirectly using pitfall trap and light trap in research land. The data was analyzed by using Shannon-Wiener diversity index. The result showed that the diversity index value in 1,80. The conclusion of the result was the diversity of insect species on monoculture was lower than polyculture land of Tamarillo in Dieng Plateau. The potential role of the insects were natural enemy and destructive insect.
\end{abstract}

Key Words: Diversity, Tamarillo, Monoculture, Polyculture

\begin{abstract}
ABSTRAK
Tamarillo (Solanum betaceaum) adalah semak, dari anggota keluarga Solanaceae. Spesies ini dibudidayakan di daerah beriklim $20^{\circ} \mathrm{C}$. Tamarillo hanya tumbuh di dataran tinggi, di atas $1000 \mathrm{~m}$ dari permukaan laut. Tujuan dari penelitian ini adalah untuk mengetahui keanekaragaman dan kelimpahan spesies serangga tanah dan untuk mengetahui peran potensial serangga yang menguntungkan dan berbahaya pada tanaman tamarillo di Dieng. Keragaman spesies serangga diperoleh dari penangkapan serangga secara langsung menggunakan jaring serangga dan secara tidak langsung menggunakan perangkap lubang dan perangkap cahaya di tanah penelitian. Data dianalisis dengan menggunakan indeks keanekaragaman Shannon-Wiener. Hasil penelitian menunjukkan bahwa nilai indeks keanekaragaman pada 1,80. Kesimpulan dari hasil ini adalah keanekaragaman spesies serangga pada monokultur lebih rendah dari tanah polikultur Tamarillo di Dataran Tinggi Dieng. Peran potensial serangga adalah musuh alami dan serangga perusak.
\end{abstract}

Kata Kunci: Keanekaragaman, Tamarillo, Monokultur, Polikultur

\section{PENDAHULUAN}

Serangga merupakan hewan yang mendominasi kehidupan di bumi jumlahnya melebihi $80 \%$ dari hewan yang ada di dunia (Grimaldi, Engel 2005). Secara antroposentris serangga dikategorikan sebagai serangga yang berpotensi merugikan yang pada umumnya tergolong dalam kelompok serangga herbivora dapat merusak tanaman sedangkan serangga yang berpotensi menguntungkan adalah kelompok serangga predator yaitu serangga yang memakan serangga lain, parasitoid yaitu serangga yang hidup menumpang pada serangga lain, dan polinator yaitu serangga yang membantu dalam penyerbukan pada tumbuhan. Kelompok serangga omnivora dapat merugikan dan menguntungkan baik secara langsung maupun secara tidak langsung (Price et al.2011). Kerusakan tanaman yang diakibatkan oleh serangga sangat ditentukan oleh jenis serangga, semakin besar potensi merusak yang dimiliki oleh serangga semakin rendah nilai ekonominya (Untung 2013). Sehingga keanekaragaman jenis serangga dan potensi peran serangga yang mengguntungkan dan merugikan pada ekosistem pertanian perlu dikelola dengan baik (Price et al. 2011).

Terung belanda merupakan buah-buahan yang memiliki kandungan vitamin A 21\%, vitamin C $50 \%$ dan vitamin E 14\% (Athar et al. 2003). terung belanda dapat dikonsumsi secara langsung dan juga diolah terlebih dahulu (Marton 2004). Saat ini buah terung belanda dibudidayakan oleh petani di daerah Dieng. Dieng merupakan daerah pusat produksi terung belanda untuk daerah Istimewa Yogyakarta dan Jawa Tengah. Daerah ini cocok untuk pengembangan produksi terung belanda karena memiliki iklim yang mendukung untuk pembudidayaan terung belanda.

Tanaman terung belanda memiliki keanekargaman jenis serangga yang saat ini belum diketahui jenisnya, sehingga perlu dilakukan penelitian untuk mengetahui keanekaragaman jenis serangga. Penelitian keanekaragaman jenis serangga yang telah dilakukan pada anggota Famili 
Solanaceae misalnya, penelitian Sanjaya (2012), pada tanaman cabai (Capsicum annum) memiliki keanekaragaman serangga dengan jumlah 15 Famili dan 9 Ordo yang diantaranya yaitu Ordo Coleoptera, Hymenoptera dan Diptera. Tanaman tomat juga memiliki keanekaragaman yang berbeda sehingga diperoleh empat spesies yang dominan, yaitu Thrips sp. (Thysanoptera), Hylaeus sp. (Hymenoptera), Aphis fabae (Homoptera), dan Macrolophus sp. (Hemiptera), Lebah Hylaeus sp (Fajarwati, 2009).

\section{BAHAN DAN METODE}

Alat dan bahan yang diperlukan dipersiapkan dalam pengambilan sampel adalah jaring serangga dengan ukuran $75 \mathrm{~cm}$ dan diameter $30 \mathrm{~cm}$, botol pembunuh dengan ukuran $100 \mathrm{ml}$, gunting, tali rapia, kertas papilot, jarum serangga ukuran $32-40 \mathrm{~mm}$, plastik $5 \times 6 \mathrm{~cm}$, botol flakon ukran $10 \mathrm{ml}$ yang telah diisi alkohol $70 \%$, jebakan serangga fit fall trap dan light trap, alat tulis, kotak perlengkapan alat dan alat yang digunakan untuk mengukur faktor abiotik meliputi anemometer untuk mengukur kecepatan angin, lux meter untuk mengukur cahaya, dan higrotermometer untuk mengukur suhu dan kelembaban. Koleksi serangga dilakukan dengan cara menangkap serangga dengan metode jelajah pada areal tanaman terung belanda baik secara langsung dan tidak langsung. Perangkap yang digunakan terdiri dari jaring serangga, fit fall trap dan light trap. Sampel serangga yang tertangkap pada tanaman terung belanda fase buah dan bunga baik secara langsung maupun dengan jaring dan jebakan dikoleksi, dikumpulkan, dicacah dan dihitung jumlahnya pada setiap perangkap dengan menggunakan hand counter. Selanjutnya faktor lingkungan seperti temperatur, cahaya, angin dan kelembaban diukur setiap penggambilan serangga. Serangga yang ditemukan diidentifikasi dengan melihat ciri morfologi pada tingkat Famili sampai tingkat spesies.
Sampel serangga imago dimasukan ke dalam botol pembunuh yang digunakan untuk membunuh serangga. Kemudian dilakukan penusukan (pinning) dengan menggunakan jarum serangga pada bagian thorax sebelah kanan, serta letakan bagian tubuh serangga sejajar dengan papan perentang. Setelah itu diberi lebel yang berisi nama tempat, lokasi, tanggal pengambilan spesimen, nama kolektor, kode lokasi, alat yang digunakan sebagai perangkap, kemudian dimasukakan ke dalam inkubator agar spesimen kering selama dua sampai empat hari. Setalah itu serangga dimasukkan kedalam box berukuran $40 \times 40 \mathrm{~cm}$ sebagai tempat penyimpanan spesimen, agar tidak berjamur box tersebut diberi kapur barus. Serangga yang berukuran kecil dimasukkan kedalam botol flakon yang telah diberi alkohol $70 \%$. Serangga yang tertangkap dianalisis jumlah dan jenis serangga dengan indeks keanekaragaman Shannon-Wienner.

$$
H^{s}=-\sum_{i=1}^{s}(p i)(\ln p i)
$$

Keterangan :

H': indeks keanekaragaman Shannon-Wienner

$\mathrm{s}$ : Jumlah spesies

pi : Proposi total sampel yang tergolong dalam spesies i

Parameter lingkungan memiliki pengaruh terhadap kemelimpahan serangga. Parameter lingkungan yang diukur meliputi temperatur udara, kelmbaban udara, kecepatan angin, dan intensitas cahaya. Pengukuran dilakukan pada saat bersamaan dengan pengambilan sampel serangga.

\section{HASIL DAN PEMBAHASAN}

Data keanekaragaman jenis serangga yang ditemukan pada tanaman terung belanda di dataran tinggi Dieng, dapat dilihat pada Tabel 1

Tabel 1. Keanekaragaman Serangga pada Tanaman Terung Belanda

\begin{tabular}{|c|c|c|c|c|c|}
\hline No. & Ordo & Famili & Genus & Spesies & Jumlah \\
\hline 1. & Blattodea & Blattidae & Periplaneta & P. americana & 2 \\
\hline 2. & Coleoptera & Chrysomelidae & Aulacophora & A. coffeae & 3 \\
\hline 3. & & Chrysomelidae & & $S p 1$ & 60 \\
\hline 4. & & Coccinellidae & Coccinella & C. transversalis & 22 \\
\hline 5. & & Elateridae & Adelocera & A. intermedia & 4 \\
\hline 6. & & Scarabaeidae & Phylophaga & Phylophaga sp & 4 \\
\hline 7. & & Scarabaeidae & Diphucephala & Diphucephala sp & 2 \\
\hline 8. & & Scarabaeidae & & $S p 1$ & 1 \\
\hline 9. & & Staphylinidae & Paedarus & P. fuscipes & 8 \\
\hline 10. & & Tenebrioinidae & Genocephalum & G. malajikum & 5 \\
\hline 11. & Diptera & Assilidae & Pormachus & P. aefianda & 10 \\
\hline 12. & & Calliphoridae & Lucilia & L. papuensis & 15 \\
\hline 13. & & Staratiomidae & Hermetia & H. remittens & 4 \\
\hline 14. & & Tachinidae & Carcelia & Carcelia $s p$ & 5 \\
\hline
\end{tabular}




\begin{tabular}{|c|c|c|c|c|c|}
\hline No. & Ordo & Famili & Genus & Spesies & Jumlah \\
\hline 15. & & Tachinidae & Thelaira & T. sumatrana & 17 \\
\hline 16. & & Tipulidae & & $S p 1$ & 8 \\
\hline 17. & Hemiptera & Aphididae & Aphis & A. gosssypii & 1700 \\
\hline 18. & & Aphididae & Chaetosiphon & C. fragaefolii & 435 \\
\hline 19. & & Cicadellia & Bothrogonia & B. addita & 2 \\
\hline 20. & & Pentatomidae & & $S p 1$ & 3 \\
\hline 21. & & Reduviidae & Cydnocoris & Cydnocoris sp & 1 \\
\hline 22. & & Tessaratomidae & Eusthenes & Eusthenes & 1 \\
\hline 23. & Hymenoptera & Apidae & Bombus & B. rufipes & 5 \\
\hline 24. & & Apidae & Xylocopa & X. caerula & 1 \\
\hline 25. & & Braconidae & Fopius & Fopius sp & 32 \\
\hline 26. & & Formicidae & Diacamma & Diacamma $s p$ & 5 \\
\hline 27. & & Formicidae & Anoplopepis & A. graciipes & 28 \\
\hline 28. & & Formicidae & Technomyrmex & T. albipes & 31 \\
\hline 29. & & Vespidae & Vespa & V. velutina & 8 \\
\hline 30. & Lepidoptera & Geometridae & Abraxas & Abraxas sp & 1 \\
\hline 31. & & Lymantridae & Eusproctis & Eusproctis $s p$ & 1 \\
\hline 32. & & Nolidae & Tympanistes & T. fusimargo & 1 \\
\hline 33. & & Nympalidae & Vanessa & V. cardui & 3 \\
\hline 34. & Mantodea & Mantidae & & $s p 1$ & 1 \\
\hline 35. & Odonata & Coenagrionidae & Ischnura & I. aurora & 36 \\
\hline 36. & Orthoptera & Acrididae & Oxya & O. chinensis & 13 \\
\hline 37. & & Grylidae & Gryllus & G. mitratus & 3 \\
\hline \multicolumn{5}{|c|}{ Total } & 2481 \\
\hline
\end{tabular}

Keanekaragaman spesies dapat digunakan untuk menyatakan struktur komunitas. Struktur komunitas dapat dinyatakan dengan keanekaragaman jenis. Keanekaragaman jenis yang tinggi menunnjukkan bahwa suatu komunitas itu sangat tinggi (Indriyanto 2006). Suatu komunitas akan memiliki keanekaragaman jenis tinggi jika disusun oleh banyak spesies dengan kemelimpahan yang sama atau hampir sama. Sebaliknya jika komunitas itu disusun oleh sangat sedikit spesies dan tidak terjadi kemerataan kemelimpahan, maka keanekaragaman jenisnya rendah.

Keanekaragaman serangga yang terdapat tanaman terung belanda memiliki nilai indeks keanekaragaman $\mathrm{H}^{\prime}=1,80$. Nilai indeks keanekargaman tersebut menunjukkan bahwa memiliki katagori keanekaragaman serangga pada tingkatan yang sedang. Rentang nilai indek keanekaragaman berkisar H' $<1$ keanekaragaman rendah, $\mathrm{H}^{\prime}=1<3$ maka keanekaragaman sedang, sedangkan H' $>3$ artinya keanekaragaman tinggi (Gazali 2014). Hal tersebut disebabkan tanaman penyusun lahan terdapat pada tanaman terung belanda seperti carica, cabai dan pohon minyak kayu putih. Selain itu juga banyak terdapat tumbuhan gulma sebagai penyusun vegetasi pada lahan tanaman terung belanda. Gulma pada lahan tersebut mempengaruhi keberadaan keragaman serangga herbivora dan musuh alaminya dalam sistem pertanian, ada beberapa gulma tertentu yang memegang peranan penting sebagai sumber pakan serangga pada tanaman terung belanda (Lutviana 2014).

Berdasarkan sifat alamiahnya peran serangga sebagai herbivora yaitu serangga yang mendapat energi dengan cara memakan bagian dari tumbuhan, seperti serangga pemakan daun, penggerek batang, pemakan akar, pemakan nektar, pemakan buah, dan penghisap cairan tumbuhan. Serangga karnivora merupakan serangga yang mendapat energi dari prey dan parasitoid, prey berupa serangga atau hewan lain. Serangga omnivora merupakan serangga yang dapat memakan tumbuhan dan seranga tertentu. Serangga pengurai merupakan serangga yang dapat mengurai sisa-sisa tumbuhan (Borror at al, 1992).

Berdasarkan hasil penelitian serangga yang ditemukan pada lahan penelitian memilik 3 peranan yaitu sebagai serangga herbivora, karnivora (predator) dan serangga omnivora. Serangga yang berperan sebagai herbivora sebanyak $46 \%$, karnivora $51 \%$, dan omnivora sebanyak $3 \%$. Peran serangga yang terbesar pada lahan tanaman terung belanda sebagai karnivora sebanyak 51\% dapat dilihat pada gambar 1. 


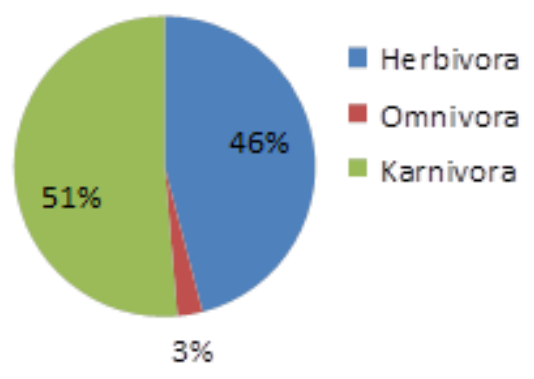

Gambar 1. Persentase Jumlah Serangga yang Didapatkan pada Tanaman Terung Belanda

Syahrawati (2010), pada tanaman terung belanda jumlah predator mencapai 2,366. Tingginya populasi predator sangat terkait dengan populasi mangsa. Populasi mangsa yang tinggi akan menarik minat predator untuk datang dan tinggal ditempat tersebut, kemudian diikuti dengan meningkatnya kemampuan predator dalam memangsa. Predator merupakan salah satu penentu tinggi rendahnya suatu populasi hama. Selain itu Faktor lingkungan juga berpengaruh terhadap populasi predator dan serangga lain yaitu suhu udara (OC), kelmbaban udara (\%), intensitas cahaya (lux) dan kecepatan angin $(\mathrm{km} / \mathrm{jm})$.

\section{KESIMPULAN}

Serangga yang tertangkap pada lahan tanaman terung belanda ditemukan 9 Ordo, 29 Famili, 32 Genus dan 37 spesies. Indek keanekaragaman serangga mencapai 1,80 hal tersebut maksuk dalam karakter keanekaragaman yang sedang. Potensi peran serangga di lahan pertanian terung belanda berpotensi sebagai musuh alami dan hama.

\section{DAFTAR PUSTAKA}

Borror, D.J., Triplehorn, C.A., and Johnson, N.F. 1992. Pengenalan Pelajaran

Serangga. Edisi Keenam. Translation Copyright. Gadjah Mada University press. Yogyakarta.

Gazali, A. 2014. Keanekaragaman dan Kemelipahan Jenis Serangga di Lahan Pertanian Stroberi (Fragaria sp) Organik dan Konvensional di Kopeng.

Grimaldi dan Engel. 2005 Insect Diversity \& Biogeography.(http://nature. berkeley.edu/ oboyski67/download/ UCSC.pdf).

Indriyanto. ir, 2006. Ekologi Hutan. Jakarta: Penerbit PT Bumi Aksara.

Lutviana. M, 2009 Keragaman spesies dan potensi peran serangga pada perkebunan Kakao monokultur dan polikultur. Samigalur

Morton,JF, 2004. Fruits of Warm Climates Creative Resource Systems, Inc. Miami, Winterville.

Price, P.W., Denno, R.F., Eubanks, M.D., Finke, D.L., and Kaplan, I. 2011. Insect Ecology. First Published. University Press, Cambridge United Kingdom.441488p.
Syahrawati, 2010. Diversitas Coccinellidae Predator pada Pertanaman Sayuran di Kota Padang.

Untung, K. 2007. Pengantar Pengelolaan Hama Terpadu (Edisi Kedua). Gadjah Mada University Press. Yogyakarta 